\title{
Las ciencias sociales hoy
}

José Llopis ${ }^{1}$

En los inicios del siglo XXI, las ciencias sociales —más que en ningún otro momento- se han visto orilladas a repensar profundamente, por un lado, sobre sus límites disciplinarios y, por otro, en la forma en que dan respuestas a los fenómenos sociales en el contexto de globalización, comprendido este como un fenómeno no solamente económico, sino con ramificaciones y expresiones políticas y culturales, configurando nuevas manifestaciones en las relaciones sociales.

Este doble reto ha significado que la histórica situación de estatus ambiguo de las ciencias sociales, en oposición al conocimiento producido desde las ciencias naturales, adquiera nuevos matices. Los esfuerzos por distinguirse y diferenciarse de las ciencias naturales han entrado en una fase en donde priman los enfoques interdisciplinarios y multidisciplinarios para afrontar los nuevos problemas sociales que adquieren un carácter global, pero con expresiones diferenciadas en todo el mundo.

En el contexto de desarrollo de las humanidades y la creciente utilización de las tecnologías en las mismas, así como los efectos sociales de los avances tecnocientíficos produciendo cada vez más una mayor implicación social de los conocimientos de las disciplinas vinculadas con la naturaleza, invitan a readecuar las reflexiones de las ciencias sociales, las cuales todavía están ancladas en concepciones decimonónicas.

Precisamente, repensar las ciencias sociales fue una preocupación de la Comisión Gulbenkian para la reestructuración de las ciencias sociales (1996), cuyo un objetivo clave era idear un nuevo programa y visión de las ciencias sociales a la luz de su relación con las humanidades y las ciencias naturales en la actualidad. Con este fin, se reunieron importantes académicos de las ciencias sociales, humanidades y ciencias naturales, bajo el liderazgo de Emmanuel Wallerstein, para reflexionar sobre el tipo de ciencia social que es necesario construir con base en el consenso entre las disciplinas. Así, la idea principal se orienta hacia la apertura de las ciencias sociales, "abrirlas" de sus límites disciplinarios que representan, en la actualidad, más una camisa de fuerza de orden intelectual, limitando su progreso.

\footnotetext{
${ }^{1}$ Universidad Nacional Autónoma de Honduras, Departamento de Documentación e Información, Dirección de Investigación Científica, UNAH: investigacionunah.informa.jll@gmail.com
} 
En este contexto, tres problemas teóricos y metodológicos son abordados en este esfuerzo por pensar las ciencias sociales. El primero trata de la separación entre el investigador y el proceso de investigación. Desde los inicios de los estudios en ciencias sociales se trató de apelar a una racionalidad científica y una visión neutral de la realidad, separando al investigador de su objeto, como si fueran elementos ajenos a una realidad social. Sin embargo, a pesar estos esfuerzos, el siglo XXI ha demostrado que no se puede separar al científico del contexto físico y social en el cual está desenvolviéndose, pues al medir y estudiar la sociedad estamos, al mismo tiempo, transformándola. Los avances en genética, el calentamiento global, las tecnologías de información y la reconfiguración de las nociones de tiempo y espacio en la globalización, han hecho más evidente la ilusión de una neutralidad científica plena, como era concebida en las décadas pasadas.

El segundo problema aborda las cuestiones relativas al espacio y tiempo como elementos internos de los análisis desde las ciencias sociales. Anteriormente se tenía la idea de que estos eran elementos cuasi inmutables, es decir, que cambiaban lentamente o prácticamente nada. Así, tanto el tiempo y como el espacio son construcciones sociales históricas y poseen diversas interpretaciones desde las humanidades y las ciencias naturales, no obstante, el avance central radica en el desarrollo de metodologías que tomen en cuenta las variables del espacio y tiempo en toda su expresión. Con ello, las diferencias entre las epistemologías ideográficas y las nomotéticas, ya casi superadas en la actualidad, serán prácticamente olvidadas.

Por último, las distinciones clásicas de las ciencias sociales en áreas de lo económico, político y social, exigen ser repensadas para su progresiva integración. Se trata de interpretar las multiciplidad de relaciones entre estas áreas artificialmente ideadas como recursos analíticos para el estudio de lo social; sin embargo, hoy en día es más visible que una perspectiva relacional aflore como una estrategia intelectual mucho más poderosa que el estudio parcelado y fragmentario de la realidad social.

De esta manera, estos tres importantes problemas que enfrentan las ciencias sociales son los desafíos que impone el siglo XXI a los científicos sociales. Asimismo, surge como una necesidad imperativa la reestructuración organizacional de las ciencias sociales a través de un consenso entre los límites de validez entre las disciplinas: los temas económicos son de vital importancia para los científicos sociales en general, así como los temas políticos para todos. Por tanto, el monopolio del conocimiento no debe estar reservado para una sola disciplina. 
Ahora queda preguntarse cómo se han expresado estos dilemas en la región latinoamericana. En la región han existido esfuerzos y proyectos intelectuales que han perseguido la elaboración de un conocimiento en ciencias sociales que tome en cuenta las condiciones del investigador como parte de un entramado de relaciones sociales en un contexto determinado. Las ciencias sociales latinoamericanas, en especial los enfoques comprometidos con una perspectiva regional, a través de la institucionalización por medio de iniciativas como FLACSO y CLACSO, han sido fundamentales para el progreso de las ciencias sociales desde mediados del siglo $X X$.

En todo caso, a pesar de adolecer de limitaciones propias del contexto de producción científica en la región, estos fueron los primeros pasos para generar conocimiento social propio desde la región, tratando de establecer un diálogo crítico con las tradiciones de pensamiento europeas y norteamericanas. Precisamente, las condiciones particulares de la región fueron una fuente inagotable de pensamiento crítico e innovador en las ciencias sociales. Se trataba de un enfoque que no aceptaba la adopción acrítica de los postulados epistemológicos europeos, sino que permitía una construcción alternativa desde y para las ciencias sociales latinoamericanas, a pesar de las limitaciones en el proceso de institucionalización.

Pensadores como Enrique Leff, Fals Borda, Pablo González Casanova, Edgardo Lander o Aníbal Quijano, han establecido reflexiones fundamentales que contribuyen al proceso de apertura de las ciencias sociales integrando, por un lado, una variedad de enfoques y perspectivas teóricas y metodológicas y, por otro, algunas veces repensado las relaciones entre espacio y tiempo. Por último, el pensamiento crítico latinoamericano ha realizado aportes sobre un enfoque holístico que pueda identificar las múltiples relaciones, en sus diferentes escalas, entre lo económico, político y social, desdibujando así la fragmentación del conocimiento.

Como panorama general se puede entender que los profundos cambios que ocurren en las sociedades latinoamericanas continúan retando a los enfoques clásicos con que los científicos sociales han estudiado la región. Por tanto, la emergencia de estudios y teorías dirigidas a "descolonizar" el pensamiento eurocéntrico han sido ampliamente difundidas en la región en los últimos años. En consecuencia, América Latina ha generado sus propios espacios para la reflexión de la pertinencia de las ciencias sociales en el actual contexto global, iniciando sus propias síntesis teóricas-metodológicas. 
En suma, las ciencias sociales en Latinoamérica hoy en día reafirman su propio camino de apertura de su producción de pensamiento social en un contexto que demanda más que nunca readecuar los límites de las disciplinas, no para ejercer una interdisciplinariedad vacía y puramente instrumental, sino que para establecer un diálogo fructífero y directo, en primer lugar, entre las disciplinas de las ciencias sociales, luego, de forma paralela, con la confrontación e integración con las ciencias naturales, una tarea que ahora es mucho más urgente ante las transformaciones sociales producto de la procesos tecnológicos y naturales resultado de la actividad humana.

La reestructuración de las ciencias sociales pasa por un ejercicio de introspección intelectual de los científicos sociales en todo el mundo, tanto de su actividad intelectual como en la forma de organización de las ciencias sociales en las universidades. Es ahí que el conocimiento generado y creado desde América Latina puede servir de base para convertirse en pieza clave del pensamiento social a nivel global, siendo una pieza angular de "apertura" de las ciencias sociales, logrando así ajustar cuentas con la herencia intelectual eurocéntrica.

\section{BIBLIOGRAFÍA}

Mejía, Julio. (2008). Epistemología de la Investigación Social enAmérica Latina. Desarrollos en el siglo XXI. Cinta Moebio 31, 1-13. Recuperado de: http://www2.facso.uchile.cl/publicaciones/moebio/31/mejia.pdf

Lander, Edgardo (comp). (2000). La colonialidad del saber: eurocentrismo y ciencias sociales. Perspectivas latinoamericanas. CLACSO, Consejo Latinoamericano de Ciencias Sociales: Buenos Aires. Recuperado de: http://bibliotecavirtual.clacso.org.ar/clacso/sur-sur/20100708034410/ lander.pdf

Wallerstein, Immanuel (coord). (1996). Abrir las ciencias sociales. Informe de la Comisión Gubelkian para la reestructuración de las ciencias sociales. Siglo XXI: México. Recuperado de: dcsh.xoc.uam.mx/sociales/Documentos/ 